\title{
Kitle Fonlaması Finansman Yöntemi: Türkiye'de Sistemin Geliştirilmesine Yönelik Öneriler
}

\author{
Mehmet Kemalettin ÇONKAR* ${ }^{*}$ Muhammet Fatih CANBAZ ${ }^{* *}$ \\ ÖZ
}

Kitle fonlaması günümüzde girişimcilerin kullanabileceği bir finansman seçeneği olarak tanınma ve geliştirilmeyi beklemektedir. Bu modern araç özünde girişimciler için bir fon temin etme aracı olarak değerlendirilse de fon sağlayanlar açısından sadece borç vermekten farklı olarak reel bir yatırıma ortak olma olanakları da sunan bir yöntem olarak farklılaşmaktadır. Özellikle Amerika ve Avrupa'da hızlı gelişme gösteren bu yöntem ülkemizde henüz Aralık 2017'de yasal çerçeveye kavuşmuştur. Kitle fonlaması fona ihtiyaç duyan girişimcilerin kitle fonlaması sitelerine fon temini için başvurmaları ile başlar. İlgili internet platformları üzerinden projelerini açık çağrı ile potansiyel yatırımcılara sunulmasıyla devam eder ve nihayetinde yatırımcıların finanse etmek istedikleri projeleri fonlaması ile süreç son bulmaktadır.

Kitle fonlaması toplumun tüm kesimlerinin kolaylıkla ulaşabileceği bir finansal araç olarak dikkat çekmektedir. Ülkemizde geçiş aşamasını yaşayan bu yöntemin hızlı gelişeceği düşünülmekle beraber sistemin yaygınlaşması için atılması gereken bazı adımlar ve alınması gereken bazı tedbirler söz konusudur. Bu çalışmada amacımız kitle fonlamasının ülkemizde geliştirilmesi adına yapılması gerekenleri ortaya koyarak değerlendirmeye çalışmak olacaktır. Çalışmanın uygulamada yapılacak iyileştirmelere ve akademik çalışmalara kaynaklık edeceği düşünülmektedir.

Anahtar Kelimeler: Kitle Fonlaması, Yatırım, Girişimci, Yatırımcı, ICO

JEL Sinıflandırması: G20, G21, G23

\section{Crowdfunding: Suggestions For Development in Turkey}

\begin{abstract}
Nowadays, Crowdfunding emerges as a common method of funding that entrepreneurs can benefit from. Besides, it is an investment method for potential investors. Crowdfunding has been developed specifically in North America and in Europe. On the other hand, it was legalized in December 2017 Turkey. The crowd funding process starts with applying to crowdfunding websites by entrepreneurs who need funding for startup. Projects are presented on the web site to potential investors through an open call; and finally, the process ends with the funding of the projects that investors would like to finance.

Crowdfunding also attracts attention as a financial instrument that all segments of society can easily reach. It is inevitable to make further improvements in order to spread this system, which is expected to develop rapidly in Turkey, to large number of people. In this study, what needs to be done in order to develop Crowdfunding in Turkey will be discussed. We believe that this study will serve as a source in academic studies and for improvements to be made in practice.
\end{abstract}

Keywords: Crowdfunding, Investment, Entrepreneur, Investor, ICO

JEL Classification: G20, G21, G23

Geliş Tarihi / Received: 29.11.2017 Kabul Tarihi/Accepted: 16.04 .2018

\footnotetext{
* Prof. Dr., Afyon Kocatepe Üniversitesi, İktisadi ve İdari Bilimler Fakültesi, İşletme Bölümü, conkar@aku.edu.tr, ORCID: 0000-0001-5378-3801

** Öğr. Gör., Afyon Kocatepe Üniversitesi, Afyon Sağlık Yüksekokulu, Sağlık Yönetimi Bölümü, canbaz@aku.edu.tr, ORCID: 0000-0002-4711-3489
} 


\section{GİRIŞ}

Sermayeye erişim veya borç temini iktisadi hayatın olmazsa olmaz kadim problemlerindendir. 16. yüzyıl ile Avrupa ve dışına doğru hızlanan ticari hayat akabinde 18. Yüzyılda sanayi devriminin İngiltere'de meydana gelmesi ile kapitalist sistem içerisinde paranın arzı ve talebi bitmeyen bir sarmal oluşturmuş ve günümüz iktisadi hayatının ayrılmaz parçalarından biri olmuştur. Bu kadim borç verme-borçlu olma ilişkisi vesilesiyle birçok borçlanma aracı ortaya çıkmış ve günümüzde klasik olarak nitelendirilebilecek araçlar oluşmuştur. Toplumların farklı nedenleri olmakla birlikte piyasalarında kemikleşen finansman araçları dışında da alternatif finansman yöntemi arayışları hep olmuştur. Türkiye'de kitle fonlaması olarak adlandırılan "Crowdfunding" yöntemi alternatif finans endüstrisinin geliştirdiği en genç finansman aracıdır (CrowdfundingHub, 2016). Son yıllarda özellikle Amerika ve Avrupa kıtalarında yoğun bir şeklide kullanılmaya başlanmıştır. Özü itibariyle klasik finansman yöntemleri ile benzer özellikleri taşıyan, uygulamada ise oyuncular ve aracılar itibariyle farklılaşan modern bir fon temin etme, fon arz etme, ortaklık kurma ve hibe yoluyla finansman aracidir.

Kitle fonlamasının finansal bir araç olarak ortaya çıkışı ve sonrasındaki hızlı gelişiminde etkili olan birçok neden sayılabilir. Bunlardan önemli olduğunu düşündügümüz ilk neden, piyasalardan borç temin edemeyen girişimcilerin, başlangıç aşamasındaki fikir sahiplerinin ve piyasada kredi dönüşü itibariyle güven eksiği yaşayan firmaların bu yöntemi kitlelerin gücünden faydalanmak amacıyla kullanma çabalarıdır. Kitlelerin gücünü temsil eden kitle fonlaması kavramı yeni bir finansman aracı gibi görünse de adı konulmamış bir yöntem olarak çok eskilere dayanmaktadır. Bu durum şu ilginç örnekle açıklanabilir, Fransa tarafından Amerika Birleşik Devletlerine yüzüncü yıl hediyesi olarak takdim edilen Özgürlük heykeli 4 Kasım 1885 günü New York'a ulaşması akabinde finansal sıkıntılar nedeniyle heykelin kaidesi Amerikan devleti tarafından hazırlanamamıştır. Bu nedenle New York'ta yaşayan gazeteci ve yayıncı Joseph Pulitzer heykelin kaidesinin yapımı için kendisinin sahibi olduğu "World" gazetesi aracılığıyla 100.000 \$ bağışlayacağını açıklayarak herkesi küçük de olsa bağış yapmaya çağırmıştır. Bu çağrı ve girişim bugünkü kitle fonlamasının erken örneği ve temel işleyişin yapı taşı olarak kabul edilmektedir. Gazeteci, yapmış olduğu bu fedakârlık sebebiyle daha sonraları gazetecilikte en prestijli ödül olarak kabul edilen 'Pulitzer' ödülünün de isim babası olacaktır (The Guru Guide, 2016). Sermaye eksiği olan bireylerin yanı sıra sistemin işlediğini gören birçok girişimci piyasalardaki yüksek faiz oranlarına katlanmamak adına kendisine bu yöntem ile zaman zaman faizsiz zaman zaman ise düşük faiz oranları ile fon temin etmeye başlamışlardır.

$\mathrm{Bu}$ yenilikçi çabalar ve uluslararası toplumun bu yeni finansal araca olan ilgisi kitle fonlaması pazarını büyütmüş ve günümüzde küresel ölçekte bakıldığında kayıtlı olarak 40 milyar dolarlık bir büyüklük meydana getirmiştir. Pazar 2012 yılında 3 milyar \$, 2013'te 6 milyar \$, 2014 yılında 16 milyar \$'a ve 2015 yılında 34 milyar \$'a ulaşmıştır (Statisticbrain, 2016). 2016 ve 2017 yılına ilişkin net bir veri olmamasına karşın büyüme hızına bakıldığında tutarın 2017 yılsonu itibariyle 100 milyar \$’ın üzerine çıkacağı düşünülmektedir. Henüz organize edilmiş bir sistem olarak 10 yıllık bir geçmişi olan kitle fonlamasının büyüme hızı dikkate şayandır. İlgili rakamlar itibariyle daha da büyüyeceğini tahmin etmek zor değildir.

Son dönemlerde üzerinde çokça tartı̧̧malar yapılan Blockchain ve cyrptocurrency sektörlerininin hızlı büyümesiyle beraber kitle fonlaması konseptinde alternatif bir yöntem daha ortaya çıkmıştır. ICO (Initial Coin Offering) olarak adlandırılan bu kitlesel fon oluşturma yönteminin işleyişi faklı olsa da özünde kitle fonlamasının türevidir. Bu yöntem bir girişim fikrine sahip şirketlerin bu fikre finansman sağlamak adına piyasaya kendi kripto paralarını sürerek toplu satış (crowdsale) yaptıkları etkinliklerdir. Satışlar yaygın olarak kullanılan kripto paralar karşılığında da yapılabilmektedir. Klasik kitle fonlamasında olduğu gibi belirli bir fon toplama süresi olan yöntemde söz konusu sürede fon toplanırsa girişim aşamasına geçilirken fon 
hedefine ulaşılamadı ise kripto paralar yatırımcılara iade edilmektedir. Olumlu sonuçlanan örneklerde crypto-token sahipleri şirket hisselerine tam mülkiyet ile sahip olurlar. İlk ICO uygulamasına girişen Mastercoin 2013 yılında kendi coinlerini satarak 5 Milyon \$ değerinde Bitcoin elde ederek ciddi bir fon rakamına ulaşmıştır. Akabinde 2014 yılında Ethereum 18 milyon dolar, 2016 yılında Waves 16 milyon dolar ve yine 2016 yılında The DAO 150 milyon Dolar elde etmiştir. Kripto para sahiplerinin üstlendiği en ciddi risk olarak kabul edilen sanal ortamda yaşanan illegal erişim problemleri The DAO'nun da başını ağrıtmıştır. İlgili fon toplamadan bir süre sonra hackerların saldırısına uğramış ve 50 milyon Dolarlık yatırımı kaybetmiştir (Crypto Türkiye, 2018).

Ülkemizde de fongogo, fonla beni, crowdfon, arı kovanı ve buluşum gibi kitle fonlaması platformları bulunmaktadır. Ancak projelerinin uluslararası platformlara nispetle düşük seviyelerde desteklendiği açıktır. Bu husus ülkemize özel birçok toplumsal farklılık ve nedenle açıklanabilir. Toplumsal refahın belirli bir seviyeye henüz ulaştı̆̆ ülkemizde finans kavramına olan psikolojik uzaklık ve yetersiz bilgi en tipik toplumsal problemlerimizdendir. Benzeri birçok nedeni sorun olarak da nitelendirebiliriz. Çalışmamızda temel amacımız ilerleyen süreçlerde sistemin gelişmesinin önünde engel teşkil edecek, karşımıza sorun olarak çıkması muhtemel eksiklikler ve yapılması gerekenler üzerinde durularak, sağlıklı bir kitle fonlaması ekosisteminin kurulmasına yardımcı olmak adına öneriler geliştirmektir.

Çalışmamızın bundan sonraki bölümünde genel hatlarıyla kitle fonlamasının tanımı ve işleyişi üzerinde durulacaktır. 3 ve 4 . bölümde kitle fonlaması modelleri üzerinde durulacak, 5 . bölümde konu hakkında yapılmış bazı çalışmalar incelenerek literatür taraması yapılacaktır. 6 . bölümde kitle fonlamasının günümüzdeki durumuna değinilerek son bölümde ise temel konumuz olan öneriler üzerinde durularak çalışma sonuçlandırılacaktır.

\section{KITLE FONLAMASININ TANIMI VE İŞLEYISŞi}

Kitle fonlaması yöntemi gelişen teknolojik hayatın ve değişen zihinlerin bir ürünü olarak nitelendirilebilir. Kitle fonlamasının en belirleyici özelliği internet üzerinden henüz tanışmadığınız belirsiz bir kitleden açık çağrıyla borç temin etme arayışı olmasıdır. Arkadaş bulma çabaları ile başlanılan bir ă üzerinden tanımadığımız kişilerle iletişim çabalarının ulaştığı son nokta onlardan hibe temin etme, destek görme ve borç talep etmeye kadar varmıştır. Bu sonuç bize internetin gücünü gösteren en ciddi çıktılardandır. Zihin değişikliği kastı ise geleneksel anlayışın dışında sanal ortamda gelişen bir ürün olarak daha çok genç jenerasyonun ilgili aracı kullanma temayülüdür. Uluslararası nitelikte olan birçok kitle fonlaması platformu incelendiğinde projelerin birçoğunun tahmini olarak 20-40 yaş arası jenerasyon tarafindan sunulduğu görülmektedir.

Belirli çalışmalarda kitlesel yatırım, kitlesel borçlanma ve kitle finansmanı olarak da isimlendirilen ve en geniş kullanılan isimlendirme ile kitle fonlaması yöntemine ilişkin literatürde karşılaşılan birkaç tanım verilerek kavrama açıklık getirilmeye çalışılacaktır.

Hazine Müsteşarlığı uzmanları tarafından hazırlanan çalışma raporunda kitle fonlaması; bir projenin veya girişim fikrinin bir grup yatırımcı tarafindan internet vasıtasıyla finanse edilmesi şeklinde tanımlanmaktadır (Onur ve Değirmenci, 2015).

Kitle fonlaması Grut (2016) tarafindan perakende yatırımcılar olarak adlandırılan sıradan insanların yeni kurulan işletmelere veya yeni bir fikre $10 £$ veya $20 £$ gibi küçük tutarlar ile yatırım yaptıkları, gelirin eşitlik esasına göre paylaşıldığı bir sistem şeklinde tanımlanmaktadır. Bununla birlikte kitle fonlamasının bu tanımda bahsedilen uygulamaları dışında birçok farklı uygulaması bulunmaktadır. Zira Grut (2016)'nın tanımı bahsedeceğimiz kitle fonlaması modellerinden yalnızca birini kastederek yapılmıştır. 
Kitle fonlaması, belirli bir proje için finansman ihtiyacı duyanlarla direkt olarak fon sağlayacak veya bağışta bulunabilecek kişileri birbirine bağlayan yeni bir alternatif finansman biçimidir. Uygulama itibariyle belirli projelere sermaye desteği bulmak için halka açık çevrimiçi çağrılar yapılması şeklinde karşımıza çıkmaktadır (The European Commission, 2017). Ayrıca Avrupa komisyonunun hazırlamış olduğu farklı bir raporda; projeleri ve işletmeleri finanse etmek için para toplamanın bir yolu ve fon arayanlara çevrimiçi platformlar vasitasıly çok sayıda insandan para toplamayı sağlayan aracı bir yöntem olarak tanımlanmaktadır (European Union, 2015).

Fonlamanın bankalar ve diğer finansal kuruluşlardan borçluya doğru yapıldığı klasik borçlanma yöntemlerinden temel farkı borcu sağlayan bir grubun varlığıdır. Aracıların olmadığı, borç verenin hangi projeye veya girişime destek verdiğini bildiği ve en önemlisi kimi fonladığına karar verebildiği özgür bir fonlama yöntemi olarak klasik yöntemlerden farklılaşmaktadır.

Kitle fonlamasında işleyiş basit olarak nitelendirilebilir. En yalın haliyle fikir sahiplerinin kitle fonlaması platformlarına üye olarak projelerini platform üzerinden açık çağrı ile sunması şeklinde gerçekleşir. Tanımlama olarak nitelendireceğimiz bu aşamada fikir sahibi öncelikle projesini tanımlamalı, kapsamını belirlemeli ve fikrin genel vizyonunu açıklamalıdır (Crowdfund.co, 2017). Bu sunumlar video, belge vesair zengin içeriklerle yapılabilmektedir. İlk aşamada platform tarafından ön kabulden geçen proje belirli bir süre ve hedef sermaye tutarı ile internet sitesinde yayınlanmakta ve ilgili projeye yatırımcı aranmaktadır. Söz konusu zaman zarfinda projenin gelişimi ile ilgili bilgilendirmeler fikir sahibi ve internet platformu tarafindan belirli aralıklarla yapılmaktadır. Belirli bir sermaye hedefi ile sunulmaya başlanan proje fonlama tutarına ulaştığında başarılı olarak kabul edilmekte ve toplanan fonlar sunum süresi dolduğunda proje sahibine yatırımı gerçekleştirmesi adına transfer edilmektedir. Sermaye hedefine ulaşamayan projelere yapılan yatırım tutarları ise yatırımcılara geri ödenmektedir. Sermaye hedefine ulaşmasa dahi toplanan tutarın fikir sahiplerine transfer edildiği örnekler bulunmaktadır (Nascimento ve Querette, 2013).

Kitle fonlaması denildiğinde uygulamada yalnızca bir model (Ödül Temelli Kitle Fonlaması) yüksek oranda karşımıza çıkmaktadır. Diğer modellerin nispeten daha az oranda kullanılmasının arkasında hukuki eksiklikler ve mevzuatı olmayışı gibi problemler yatmaktadır. Bu noktada kitle fonlaması uygulamaları denildiğinde iki ana başlık altında farklılaşan modeller karşımıza çıkmaktadır. Bu iki ana başlık sonuçları itibariyle finansal sonuç doğurmayan ve finansal sonuç doğuran olarak bölümlendirilebilir. İlgili modeller belirtilen başlıklar altında sinıflandırılmıştır.

\section{FINANSAL SONUÇ DOĞURMAYAN KITTLE FONLAMASI MODELLERI}

Finansal sonuç doğurmayan modeller iki farklı şekilde uygulanmaktadır. Bunlardan ilki bağış veya hibe olarak kabul edebileceğimiz kitle fonlaması modeli diğeri ise fonlama karşıllğında fon temin eden girişimcinin projesinin başarıya ulaşması halinde taahhüt ettiği bir ödülün var olduğu kitle fonlaması modelidir.

\subsection{Bağış Temelli Kitle Fonlaması (Donation-based Crowdfunding)}

Fonlama yapan bireylerin maddi bir çıkar beklentisi olmaksızın daha çok belirli hayır işlerinin yapılması için tercih ettiği fonlama türüdür. Yatırımcıların projenin gereken sermaye büyüklüğüne ulaşması adına yaptığı küçük miktarlarda bağışlar olarak karşımıza çıkmaktadır. Bu modelde hayırseverlik, yardımlaşma ve toplumsal destek motivasyonu ön plana çıkmaktadır 
(Zhang, ve diğerleri, 2016). Bu model aracılığıyla birçok sosyal sorumluluk projesi gerçekleştirilmiştir. En genel örneği okullarda kütüphane kurulması şeklinde görülmektedir. Uluslararası olarak bakıldığında bağış yoğun portal türlerine örnek olarak GoFundMe ve Crowdrise örnek verilebilir.

\section{2. Ödül Temelli Kitle Fonlaması (Reward-based Crowdfunding)}

Destekçilerin parasal değeri olmayan ürünler veya ödüller karşıllı̆ında girişim projelerine destek sağladığı kitle fonlaması modelidir. Örneğin; çıkarmayı planladığı müzik albümüne destekçi arayan sanatçının başarıya ulaşması halinde destekçisine bir albüm göndermesi şeklinde gerçekleşebilir. Uygulamada en çok karşılaşılan ve kitle fonlaması denildiğinde ilk akla gelen yöntem olarak da kabul edilmektedir. Bireylerin yeni bir ürün geliştirmek ve kurumların ise çalışmaya başlamak için fon talep ettikleri kitle fonlaması modelidir.

Birçok teknolojik ürün, film projeleri ve kuruluş aşamasındaki şirket bu yöntemle başarıya ulaşmıştır. Bunlardan en çok bilineni Kickstarter üzerinden tanıtımı yapılan "Pebble" adı verilen akı1lı saat projesidir. Proje 66.673 destekçi sayısına ulaşarak toplamda 12,8 Milyon dolar fonlanmıştır (Stark, 2016). İlk modelinden sonraki geliştirilmiş sürümleri de kitle fonlamasına konu edilmiş ve saatin toplam fonlama rakamı 20 Milyon dolara ulaşmıştır (Crowdfundingblog.com, 2017). Ödül temelli kitle fonlaması birçok ülkede ve hâlihazırda ülkemizde de en yoğun uygulanan kitle fonlaması modeli olma özelliği taşımaktadır. Bu yöntemin yoğun olarak kullanıldığı portal türünde ise en bilinen örnekler şunlardır: Kickstarter, Indiegogo.

\section{FINANSAL SONUÇ DOĞURAN KITLE FONLAMASI MODELLERİ}

$\mathrm{Bu}$ fonlama başlığı altında bahsedilecek olan modellerde fon sağlayan bireyler projenin başarıya ulaşması halinde maddi haklar veya kazançlar elde etmektedir. Bu tip kitle fonlaması uygulamaları genel manada yatırıma ortak olma ve borç karşılığı faiz getirisi elde etme uygulamaları olarak görülmektedir.

\subsection{Borç Temelli Kitle Fonlaması (Debt-based Crowdfunding)}

Borç temelli kitle fonlaması, borç verenin projeye finansman sağladığı ve borç alanın ise bunun karşı1lı̆ında faiz gideri ödediği bir borçlanma yöntemidir. Fon sağlayıcılar sabit faiz getirisi bekledikleri bir girişime destek olarak hem maddi çıkar elde etmekte hem de yeni bir fikrin gelişmesine katkı sağlamaktadırlar.

Borç temelli kitlesel fonlama ürünlerini daha çok sabit getiri isteyen ve finansal amaçlarına ulaşmada kolaylık arayan yatırımcılar desteklemektedir. Şirket varlıkları ile teminat altına alınmış olan bu borçlanma türü teminatsız borçlanmaya göre daha güvenli görülmekte ve yatırımcılar tarafından desteklenmektedir. Bu kapsamda faaliyet gösteren portal türlerine: Prosper, FundingCircle, LendingClub gibi yapılar örnek olarak verilebilir (Futko, 2014).

\subsection{Hisse Temelli Kitle Fonlaması (Equity-based Crowdfunding)}

Hisse temelli kitlesel fonlamada en basit haliyle girişimciler projelerine ortak aramaktadırlar. Fon sağlayıcılar ilgili projeye destek vermeleri halinde esasında şirket tarafından ihraç edilmiş hisse senetlerini satın almaktadırlar. Bu model öz sermaye ortaklığı olarak görülmelidir. Model ekonomik anlamda en geniş pozitif çıktıyı üreten model olarak 
zikredilmektedir. Ülkemizde mevzuat çalışmalarının yapılmasındaki asıl sebeplerden biri olan modelin bu nedenle ilerleyen süreçlerde en yoğun kullanılacak kitle fonlaması modeli olması beklenmektedir. Massolution 2013 kitle fonlaması endüstrisi raporuna göre Hisse Temelli Kitle Fonlaması modeli diğer tüm modellere kıyasla 40 kat daha hızlı büyümektedir (Wagner, 2014).

Hisse temelli kitle fonlamasına arac1lı eden uluslararası platformlara ise İngiltere'de faaliyet gösteren Crowdcube, FundedByMe, Companisto ve Invesdor örnek olarak gösterilebilir.

\section{LITERATÜR TARAMASI}

Kitle fonlaması konusu ülkemizde de yakın ilgi görmektedir ve 2017 yılsonunda gerçekleşen yasalaşma sürecinden sonrada ilginin artacağı düşünülmektedir. Kitle fonlaması hakkında uluslararası alanda birçok makale, köşe yazısı ve kitap bulunmaktadır. Hem uluslararası alanda hem de ülkemizde yapılmış olan bazı çalışmalar tablo halinde aşağıdaki şekilde sıralanmıştır.

Tablo 1: Literatür Özetleri

\begin{tabular}{|c|c|c|}
\hline Yazar/Yazarlar & Yll & Öz \\
\hline Andrea Ordanini & & Çalışmada Kitle fonlaması analiz edilerek, kitle fonlaması \\
\hline Lucia Miceli & & platformlarının yatırım araçlarının uygulanabilirliği \\
\hline Marta Pizzetti & & kanıtlanmaya ve bu tip platformların ortaya çıkması \\
\hline A. Parasuraman & 2009 & gerekliliği ortaya koyulmaya çalışılmaktadır. \\
\hline
\end{tabular}

Çalışma geniş bir içerik sunmaktadır. Sırasıyla çalışmada;

Kitle fonlaması küçük çapta girişimler üzerine odaklanarak alternatif bir finansman yöntemi olarak tartışılmaktadır.

Crowdfunding hakkında modelleri dâhil bir açıklama yapılarak mevcut araştırmaları tartışılmaktadır. Finans kaynağı olarak crowdfunding için girişimci tercihlerini etkileyen faktörleri açıklanmaktadır.

Armin Schwienbacher Benjamin Larralde

\section{Mustafa Ergen}

Jason Lau

Kuntay Bilginoglu
2010 çalışan girişimcilere ve araştırmacılara önerilerde bulunulmaktadır. fonlaması ve potansiyeli genel hatlarıyla açıklanmıştır.

Çalışmada girişimcilerin fonlama süreçlerinde başarı veya başarısızlık dinamikleri incelenmiştir. Başarılı finansmanda coğrafyalara bağlı olarak değişiklik gösterse de projenin kalitesi ve girişimcinin ağı başarı̀ı etkileyen önemli

Ethan Mollick
faktörlerden olarak tespit edilmiştir.

Çalışmada kitle fonlaması modellerinden hisse (kar paylaşımı) temelli fonlama yöntemi ile Ödül (Ön sipariş) temelli fonlama modeli mukayese edilmiştir. Yatırımcıların fonlama yöntemi ne olursa olsun toplum faydasını gözeten

Paul Belleflamme

Thomas Lambert

Armin Schwienbacher

Mustafa Halid Karaarslan
2013 projeleri desteklediğini, girişimcilerin ise öz kaynak ortaklığından ziyade ön sipariş veya ödül temelli fonlama yöntemini tercih ettikleri sonucuna varmışlardır.

fonlaması ve sosyal pazarlamanın nasıl işlediği


açıklanmaktadır.

\begin{tabular}{lll}
\hline $\begin{array}{l}\text { Nuray Atsan } \\
\text { Eda Oruç Erdoğan }\end{array}$ & 2015 & $\begin{array}{l}\text { Çalışmada kitle fonlaması genel hatları, işleyişi ve } \\
\text { modelleriyle açiklanmıştır. }\end{array}$ \\
\hline Gareth Halfacree & 2015 & $\begin{array}{l}\text { Çalışmada kitle fonlaması aracıllı̆̆ıla başarıya ulaşan } \\
\text { projelerden bahsedilmektedir. }\end{array}$ \\
\hline Batu Anadolu & 2016 & $\begin{array}{l}\text { Çalışmada kitle fonlamas tanımlanmış, gelişimi } \\
\text { incelenerek farklı uygulama sahalarına değinilmiştir }\end{array}$ \\
\hline Ayşen Akyüz & 2016 & $\begin{array}{l}\text { Çalışmada, kitlesel fonlama kavramı, fonlama süreci, } \\
\text { fonlama platformları, klasik finans yöntemleri ile farkları } \\
\text { ve katıllımciların motivasyonları incelemektedir. }\end{array}$ \\
\hline
\end{tabular}

Kitle fonlaması platformlarına sunulan projelerin genellikle başarısızlıkla sonuçlanması nedeniyle bunun sebepleri ve başarılı bir proje için gerekli faktörleri incelemişlerdir. Sonuçta başarıyı etkileyen üç gizi şu şekilde belirlemişlerdir.

1.Başarı ne söylediğiniz değil sizin kim olduğunuzdur!

2.Başarı sizin tanıdıklarınızdan değil sizden ilham alanlardan gelir!

Adam J. Bock Denis Frydryc

The Guru Guide -

Luke Scanlon

Drummond Gilbert

3.Başarı nasıl başladığınız değil nasıl bitirdiğinizle ilgili (Brüntje \& Gajda, 2016)dir!

Kitle fonlamasının tarihi, potansiyeli ve yöntemlerinden bahsedilerek

platformlar araclığıyla başarıya ulaşmak için gerekli önerilerde bulunulmuştur.

Çalışmada Türkiye'deki kitlesel fonlamaya konu faaliyetlere destek verenlerin bu kararı vermedeki motivasyonları araştırılmıştır. Sonuç olarak temel motivasyonlar (1) Ödül avcıllğı, (2) yardımlaşma, (3) sosyal sorumluluk ve (4) duygusal bağ olarak belirlenmiștir.

Murat Seyfi

Ayda Uzunçarşı1lı Soydaş

Deniz Güven

Çalışmada kitle fonlaması sitelerinin halkla ilişkiler aracı olarak nasıl değerlendirilebileceği araştırılıp kitle fonlaması yönteminin etkin bir halkla ilişkiler aracı olarak kullanılmasına yönelik öneriler geliştirilmiştir.

Yerel Kitle fonlaması platformlarının uluslararası örneklere kıyasla neden başarısız olduğu araştırılmıştır. Sonuç olarak yerel sitelerde kullanılabilirlik sorunları olduğu tespit

Sezen Kayhan

2017 edilmiştir.

Kaynak: Bu çalışmanın yazarlarınca düzenlenmiştir.

İlgili makale çalışmalarının yanı sıra başı başına konu hakkında kitaplar da yayınlanmıştır. Bunlara Dennis Brüntje ve Oliver Gajda tarafindan editörlüğü yapılan "Crowdfunding in Europe - State of the Art in Theory and Practice" ve Florian Danmayr tarafindan hazırlanan "Archetypes of Crowdfunding Platforms - A Multidimensional Comparison" isimli eserler örnek verilebilir. 
Kitap çalışmalarının yanı sıra kitap bölümlerinde de konuyu artık sıkça görmekteyiz. Örnek olarak Jerry Fitzgerald, Alan Dennis ve Alexandra Durcikova tarafindan hazırlanan "Business Data Communications and Networking (Eleventh Edition)", Tatiana Bazzichelli ve Geoff Cox tarafindan editörlüğü yapılan "Disrupting Business: Art and Activism in Times Of Financial Crisis", Mahmoud Mohieldin ve Djordjija Petkoski’nin editörlüğü yaptığ "Financing Sustainable Development Ideas for Action" ve son olarak Sharon Y. Tettegah'ın editörlügünü yaptığı "Emotions, Technology, and Social Media" isimli eserlerdeki kitap bölümlerine örnek verilebilir.

\section{KITTLE FONLAMASININ GÜNÜMÜZDEKİ DURUMU}

Günümüzde kitle fonlaması küresel ölçekte bakıldığında kayıtlı olarak 40 milyar dolarlık bir büyüklük meydana getirmiştir. Pazar 2012 yılında 3 milyar \$, 2013'te 6 milyar \$, 2014 y1lında 16 milyar \$'a ve 2015 y1lında 34 milyar \$'a ulaşmıştır (Statisticbrain, 2016). Dünya bankasının yayınlamış olduğu (2013) "Gelişen Dünyada Kitle Fonlamasının Potansiyeli" isimli raporda 2025 yılında ilgili tutarın 96 Milyar Dolar seviyesine ulaşacağı tahmin edilmekle beraber 4 yıl içerisinde 13 kat büyüyen pazarın daha büyük bir artış göstermesi şaşırtıcı olmayacaktır. 2016 ve 2017 yılına ilişkin net bir veri olmamasına karşın büyüme hızına oranla tutarın 2017 yılsonu itibariyle 100 milyar \$'ın üzerine çıkacağı düşünülmektedir. Henüz organize edilmiş bir sistem olarak 10 yıllık bir geçmişi olan kitle fonlamasının büyüme hızı dikkat çekicidir ve gelecekte pazarın büyüyeceğini tahmin etmek zor değildir.

Ülkemizde de fongogo, fonla beni, crowdfon, arı kovanı ve buluşum gibi kitle fonlaması platformları bulunmaktadır. Ancak projelerinin uluslararası platformlara nispetle düşük seviyelerde desteklendiği açıktır. İlgili platformların yalnızca ödül temelli veya bağış temelli kitle fonlaması yapması da rakamların düşük olmasında önemli faktörlerdendir. Ülkemizde bu platformlar aracılığıyla yapılmış olan fonlama tutarları yaklaşık 500 bin TL tutarında ve destekçi sayısı ise henüz 3 bine yaklaşmaktadır (Atsan ve Erdoğan, 2015). En etkin ve kullanıcı dostu kitle fonlaması platformları ise fongogo ve arkkovanı platformları olduğu görülmektedir.

\section{KİTLE FONLAMASI UYGULAMASININ TÜRKIYE'DE GELISSMESINE ILISSKIN ÖNERILER}

Kitle fonlaması uygulaması daha çok erken aşama ve yenilikçi girişim şirketlerini desteklemek isteyen gelişmekte olan ülkeler için elverişli finansal bir araç izlenimi vermektedir. Kitle fonlaması pratiğinde sıkça karşılaşılan teknolojik ürünlerin fonlama başarısının yüksek oluşu bu imajı desteklemektedir. Gelişmiş ülkelerdeki uygulamaların ve toplumsal eğilimin incelenmesiyle elde edilecek bilgiler 1şı̆̆ında bizim gibi ülkelerde de uygulamanın yaygınlaştırılması yönünde öneriler geliştirilebilir. Bu yaklaşımla bu çalışmanın yazarları da aşağıdaki önerileri ilgililerin dikkatine sunmakta yarar görmekteyiz.

\subsection{Ekonomik, Teknik ve Siyasi Ortam}

$\mathrm{Bu}$ yöntemin bir ülkede gelişme zemini bulabilmesi, o ülkenin ekonomik, teknik ve siyasi koşullarıyla büyük ölçüde bağlantılıdır

Özellikle hisse veya ortaklık temelli kitle fonlaması yöntemlerinin gelişimi açısından ülkenin AR-GE ve yenilikçilik kapasitesi, şirket kurma ve tasfiye etmenin kolaylığı da küçük 
sermaye sahiplerinin çok sayıda ortakla birlikte yatırım yapma ve dolayısıyla bu biçimde fon temin etme talebinin artmasına yol açacaktır.

Öte yandan ülkede ekonomik ve siyasi istikrarın sağlanmış olması, tasarrufların reel yatırımlara yönelmesi açısından en önemli faktörlerdendir. Bireylerin yatırım yapma eğilimleri belirli temel ihtiyaçların karşılanması akabinde ortaya çıkmaktadır. Bu temel ihtiyaçları fiziki ihtiyaçlar, güvenlik, eğitim ve istihdam olarak belirtebiliriz. Bu temel ihtiyaçlardan eğitim sağlıklı bir ekonomik gelişme için anahtar unsurdur. Eğitim aşamasında kazandırılan yenilikçi ve girişimci düşünme yeteneği ilerleyen aşamalarda olumlu etkiler gösterecektir. Okullarda verilecek olan herkesten farklı düşünebilme ve yeniliği özendirme çabaları daha yaratıcı bireylerle girişimlerin hızlanmasına katkı sağlayacaktır (Uyar, 2018). Temel ihtiyaçları karşılanan bireyler kendini gerçekleştirmek adına daha çok risk almaya ve girişim yapmaya yönelmektedirler. Güvenilir bir girişim ortamının tesisi ancak teknik, ekonomik ve siyasi istikrarın sürekliliği ile mümkündür.

\subsection{Girişimcilik Kültürünün Geliştirilmesi}

Kitle fonlaması uygulamasının yaygınlaşması öncelikle ülke içinde girişimcilik kültürünün ne ölçüde var olduğuna bağlıdır. Bir ülkedeki düzenleyici kurumlar yeni bir finansal araç veya bir iş faaliyeti ile ilgili risk düzeyini şekillendirerek, işleyişi kolaylaştırarak girişimciliği teşvik edebilmektedir (Onur ve Değirmenci, 2015).

Girişimcilerin sürekli iletişim halinde olmalarını sağlayacak etkinlikler, sürdürülebilir işletmeler yaratmak çabasındaki bilgi, deneyim ve strateji ihtiyacı olan küçük çaplı girişimlerin ücret ödemeden bir araya gelmesini sağlayarak onları desteklemiş olmaktadır.

İlgili kamu kurumları ve üniversiteler tarafından iş planlarıyla ilgili yarışmalar düzenlenmesi, ödüllü toplantılar tertip edilmesi, bilgilendirici ve kafa karışıklıklarının giderilmesine dair etkinlikler düzenlenmesi, hibe ve benzeri politikaların üretilmesi veya doğrudan projelere sponsorluk yaparak da girişimcilik kültürünün gelişmesine destek verilmesi mümkündür.

Ayrıca girişimci nitelikte insanları çoğaltmaya yönelik olarak hem lise hem üniversite müfredatlarında girişimcilik derslerinin yer alması, lisans ve lisansüstü programlarda yenilikçilik, inovasyon ve araştırmacılık kültürünü geliştirmeye yönelik programların çoğaltılması da önemle üzerinde durulması gereken konulardandır.

\subsection{Güvenli Bir Girișimcilik Ekosistemi}

Güvenli bir girişimcilik ekosistemi girişimciliği destekleyen güvenli ve organize bir ortamı ifade etmektedir. Güvenli bir girişimcilik ekosisteminin oluşmasını temin etmek adına ise en önemli hususlar; girişimciler ve fon sağlayanlar arasında tesis edilecek güven ortamıdır. Kitle fonlaması bir girişimcinin yeni bir girişim başlatması veya mevcut işi geliştirmesi amacıyla kaynak aramasına dayanan bir sistemdir. Kitle fonlaması platformları veya sosyal ağlar ise tarafların karşı1ıklı güven ortamına dayalı ve gönüllü olarak katıldıkları oluşumlardır. Bu güven üyelerin bilgi paylaşımını kolaylaştır. Güven eksikliği olan bir ortamda kitle fonlaması sisteminin gerçekleştirilebilmesi çok zor olacaktır (Onur ve Değirmenci, 2015). Yatırımcıların toplanan fonları uygun biçimde kullanamaması ve yatırımlardan beklenen geri dönüşün sağlanamayacağı hakkında duyulan endişe girişimcilik ekosistemini zehirleyecek ve sistemin gelişmesinin önünü kesecektir.

Girişimciliği destekleyici bir ekosistem oluşturulması için, devletin girişimciliği kolaylaştıran politikaları, düzenlemeleri ve destekleyici kurumları, finansal kaynak edinme 
alternatifleri, kaliteli insan sermayesi ve yeterli altyapı imkânları önemli unsurlardandır (Atsan ve Erdoğan, 2015).

\subsection{Yeni Girişimcilerin Gelişmesine Destek Verecek Kuluçka Merkezlerinin Artırılması}

Genellikle bir teknopark içerisinde yerleşmiş, teknik üniversite veya araştırma enstitüsü ile birleşmiş olan bir kuluçka merkezi, iyi çalışma alanları ve paylaşılmış ofis imkânları ile birlikte danışma ve kolaylaştırma odaklı hizmetler sunarak yeni filizlenen girişimcilerin geliştirilmesine destek sağlarlar.

Kuluçka merkezleri girişimcilere düşük maliyetli ofis ve laboratuvar imkânı, yönetsel hizmetler, kütüphane ve veri kaynaklarına ulaşım, deneyimli danışmanlar, üniversite öğrencilerinden oluşan ucuz işgücü, teknik uzman desteği sağlar. Ayrıca resmi makamlar ve bankalarla ilişkilerinde yardımcı olurlar. Böyle bir ortamda girişimcilerin karşılaştıkları sorunları aşmaları kolaylaşacaktır. Bu durum dolaylı olarak yatırım yapmak isteyenlerin yeni girişimlere finansal destek sağlama cesaretini artıracak bir ekonomik iklimin gelişmesini hızlandıracaktır.

\subsection{Başarısızlık ve İflasa İlişkin Kamuoyu Algısını Daha Ilımlı Hale Getirmek}

Kitle fonlaması yatırımları için gerekli koşulların oluşturulması çerçevesinde girişimcilerin işlerinde başarısız olma riskini göze almalarını sağlayacak bir iklim oluşturmak da önemlidir (Onur ve Değirmenci, 2015).

Bir girişimin başarısız olması halinde ilk akla gelecek faktörün kötü niyet ve suistimal olmayabileceği, girişimcinin etkileyemeyebileceği faktörlerin de söz konusu olabileceğinin düşünülmesi girişimcilik motivasyonunu daha hızlı geliştirebilir. Bu anlayışın yaygın olduğu bir sosyal ortamda girişimlerin başarısı da paralel olarak artacaktır. Dolayısıyla proje bazında girişimcilere finansal destek sağlayabilecek yatırımcılar da daha hızlı çoğalacaktır. Başka bir ifadeyle hatalara ve başarısızlığa toleransın yüksekliği de girişimciliğe yönelme ve onlara finansal destek sağlama isteğini daha da arttıracaktır.

\subsection{Teknolojinin ve Sosyal Ağların Etkin Kullanımı}

Teknolojik altyapı imkânlarının varlı̆̆ı ve etkin bir biçimde kullanımı kitle fonlaması sisteminin gelişebilmesi için vazgeçilmez bir gerekliliktir. Yöntemin iyi çalışabilmesi için bireylerin mobil veri ağlarına ve güvenilir internete erişimlerinin rahat ve hızlı olması gerekmektedir. Bununla beraber etkisini her alanda hissettiğimiz sosyal ağlarda ilgili projelerin öncelikle yakın çevrede paylaşılması ve destek çağrısı yapılması projenin geleceği açısından gerekli görülmektedir. Projelerin kitle fonlaması platformlarının yanı sıra diğer sosyal ağlarda sunulmasının önemini fonlama hedefinin \%30 oranında yakın çevreden sağlanması gerçeği ile açıklayabiliriz. Bu çekirdek ağın desteği fonlamanın başarısını etkileyen en önemli unsurlardan kabul edilmektedir (CanadaMediaFund: 2018).

Bir girişimin kitle fonlaması platformu aracılığıyla kaynak temin etmesini kolaylaştıracak ve hızlandıracak belirli faktörler bulunmaktadır. Bunlar; girişimcilerin sosyal ağları hangi yoğunlukta kullandıkları, projeleri ne kadar iyi hazırlanmış ve detaylandırılmış oldukları, ürünü sosyal ağlarda ne ölçüde tanıttıkları ile ilişkilidir. Bununla beraber platformlar açısından teknolojiyi iyi kullanmak sürecin sağlığı açısından ayrıca önem arz etmektedir. Ülkemizde yapılan bir araştırmaya göre kitle fonlaması platformlarının kullanımında verimlilik, etkinlik ve tatmin açısından problemler tespit edilmiştir. Araştırmaya konu katılımcıların kullanım açısından karşılaştıkları sorunlar, nasıl bağış yapılacağının anlaşılamaması, 
yönlendirmelerin yetersizliği, hesap açmadan bağış yapılamaması, site içi aramaların yetersizliği, sayfalar arası yönlendirme hataları, site tasarımının karışıklığı, fonlama aşamalarının zaman alıcı olması ve genel site işleyişini anlamak için ciddi çaba sarf etmenin gerektiği şeklinde toplanmıştır (Kayhan, 2017). Fonlama rakamlarının kitle fonlamasının ana vatanı olan ülkelerde profesyonelce faaliyet gösteren platformlarda dahi \%30-40 arasında olduğu dikkate alındığında ülkemizde başarı oranlarının düşük olması bu şartlar altında normal karşılanabilir.

Kaynak teminindeki başarı projenin niteliği ve kalitesiyle de doğrudan ilgilidir. Projenin kalitesi ise projenin platformda profesyonelce ve inandırıcı biçimde sunulmasıyla birlikte, bilgilerin açık, anlaşılır ve yeterli ayrıntıya inerek sunuluşuyla da ilgilidir. Ayrıca girişimcinin projesinin başarıya ulaşacağına ilişkin güveni, tutkusu ve heyecanının da sosyal ağlarda sunulması ve bu sunumunda yatırımcılara iyi yansıtılması gerekir. Proje sunumlarında birçok kitle fonlaması platformunda özellikle tavsiye edilen yöntem olan video çekim teknolojisinden etkin bir şekilde faydalanan projelerin daha başarılı olması teknolojinin ve sosyal ağların etkin kullanımının önemini bir daha ortaya koymaktadır.

\section{SONUÇ}

Çalışmamızda ülkemizde henüz yeterince tanınmayan kitle fonlaması finansman yönteminin tanıtılması, uygulamanın yaygınlaştırılabilmesi için ne gibi önlemlere başvurulabileceği değerlendirilmeye çalışılmıştır. Kitle fonlaması, neoliberal kapitalist sistem çerçevesinde gelişmiş olan en yeni yöntemlerden biridir. Kitle fonlaması tek başına yatırım potansiyeli olmayan çok sayıda yatırımcının küçük meblağlar göndererek bir girişimi internet platformu üzerinden fonlanmasına veya bağış yapmasına imkân tanıyan yeni nesil bir finansman aracıdır. Kitle fonlamasının bir finansman aracı olarak ortaya çıkışı ve gelişmesinin nedeni mevcut finansman kurumlarından ve araçlarından fon temin etmesi zor olan küçük ve riskli görünen ancak ümit vadeden başlangıç aşaması proje sahibi girişimcilere, projelerini gerçekleştirmekte daha kolay elde edebilecekleri bir finansman seçeneği sunuluyor olmasidır.

Kitle fonlaması uygulaması dört biçimde karşımıza çıkmaktadır. Bă̆ı̧ temelli, ödül temelli, borç temelli ve hisse temelli kitle fonlaması. Hali hazırda Amerika ve Avrupa'da kitle fonlaması uygulaması önemli tutarlara ulaşmıştır. Ancak ülkemizde henüz yeterince bilinmemekte ve kullanılmamaktadır. Şu anda yasal çerçeve henüz tam anlamıyla pratiğe dönüştürülemediği için belirsizlikler içermektedir. Dolayısıyla ülkemizde bağış ve ödül temelli kitle fonlaması çok küçük çapta uygulama alanı bulabilmektedir.

$\mathrm{Bu}$ yöntemin yaygın bir uygulamaya kavuşabilmesi için her şeyden önce kitle fonlama platformlarına; üzerinde durulmaya değer, cazip niteliklerde ve yeterli sayıda proje başvurusu yapılmalıdır. Kitle fonlaması platformlarına başvuran projelerin profesyonel bir hikâyeden yoksun olması ve fikirlerin yaratıcı bir proje kapsamına girmeyişi fonlamanın önünde ciddi bir engel teşkil etmektedir. Yüzlerce proje arasında yatırımcılarca fark edilmek isteyen proje sahiplerinin projenin beklenen etkisine dair ciddi ön çalışmalar ve sunum hazırlıkları yapmaları gerekmektedir (Bock \& Frydrych, 2016). Birçok fonlamaya değer proje kendini iyi ifade edemeyişi sebebiyle yatırımcılar tarafından fark edilememektedir. Bu sorunun hem girişimciler hem de destekçiler açısından aşılması için ülkede ekonomik ve teknik eğitim imkânlarının belirli bir düzeye ulaşmış olması, sadece çok kazanç elde etmek için değil, yaptığı işten maddi olduğu kadar manevi tatmin elde etmek biçiminde bir motivasyona sahip yatırımcıların da çoğalması da önemlidir.

Ülkemizde yalnızca ödül temelli ve bağış temelli kitle fonlaması yöntemleri kullanılmaktadır. $\mathrm{Bu}$ nedenle projelerin büyük çoğunluğu sosyal sorumluluk kapsamında girişimlerden oluşmaktadır. Bu durum kullanıcılar tarafından o kadar abartılmaktadır ki çocuğunun yurt dışında yükseköğretim masraflarını karşılamak isteyen ailelere dahi 
rastlanılmaktadır. Benzeri birçok proje havuzunda yarışan yatırıma değer proje sahiplerinin destekçiler nazarında kabul edilebilir ölçüde iyi sunum yapmaları ve desteğe değer olduklarını iyi anlatmaları gerekmektedir. Aksi takdirde birçokları gibi sonuç girişimin projeler çöplüğünde yer alması olacaktır. Kitle fonlamasının ve platformlarının belirli bir olgunluğa ulaştığı Amerika'da dahi başarı oranları düşüktür. Kickstarter'ın kendi istatistiklerine göre, projelerin yalnızca yüzde 44 'ü fonlama hedefine ulaşmaktadır. Yaklaşı 60.000 projeden yaklaşık 40.000 'i hedeflerinin yalnızca yüzde 20'sine kadar ulaşabilmektedir. Bununla birlikte Indiegogo'nun kendi verilerine göre başarılı proje oranı \% 34 olarak raporlanmıştır (Strohmeyer, 2013).

Kitle fonlamasının ülkemizde geldiği aşama dikkate alınarak çalışmamızın kısıtları şu şekilde belirtilebilir; yasanın ilerleyen süreçlerde ne gibi yenilikleri doğuracağının bilinmemesi, sonuçlarının tahmin edilemiyor oluşu ve iki model dışında uygulama pratiğinden yoksun oluşumuz. Bu kısıtlar önerilerimizin de kapsamını daraltmaktadır. Diğer modellerin uygulama alanı bulması sonrasında ilgili modellerin özelde veya genel olarak nasıl geliştirilmesi gerektiğine dair öneriler sunma kabiliyetine sahip olunacaktır. Bu çalışmanın devamında yasanın işlerlik kazanmasıyla paralel olarak modellerin özelde çalışılması ve tercih edilme açısından karşılaştırılmalar yapılması yeni çalışmalarda karşımıza çıkabilecek konulardandır. Özellikle ortaklık (hisse) temelli modelin ekonomiye cari olarak direkt değer katacağından hareketle konunun akademik olarak üzerine düşülmesi gereken bir husus olduğu muhakkaktır.

Çalışmamızın sonucunda yöntemin ülkemizde uygulanmasının geliştirilmesi ve yaygınlaştırılması için alınabilecek önlemleri şöyle sıralayabiliriz.

- Öncelikle cazip niteliklerde yeterli sayıda proje fikrinin ortaya çıkması gereklidir. Bunun için ülkede ekonomik ve teknik eğitim imkânlarının yeterli düzeye ulaşması, ekonomik ve siyasi istikrarın sürekliliğine ihtiyaç vardır.

- Girişimcilik kültürünün geliştirilebilmesi ve güvenli girişimcilik ekosisteminin oluşturulması. Bu amaçla kuluçka merkezleri oluşturulması, rehberlik hizmetleri sunulması, lise ve üniversite müfredatında yenilikçilik ve araştırmacılık kültürünü geliştirmeye yönelik programların çoğaltılması önem taşıyan hususlardır. Üzerinde durulacak diğer husus ise girişimciler ve fon sağlayanlar arasında güven ortamının sağlanmasıdır.

- Girişimcilerin işlerinde başarısız olma riskini göze almalarını sağlayacak bir kültürel iklimin oluşması da önemlidir. Bir girişimin başarısızlığında ilk akla gelecek faktörün suiistimal olmayabileceği, girişimcinin etkileyemeyebileceği faktörlerinde söz konusu olabileceğinin düşünülmesi gerektiği fikrinin yaygın olduğu bir sosyal ortamda girişimcilik daha hızlı gelişebilir.

- Teknolojik altyapının yeterliliği ve bireylerin sosyal ağları, interneti güvenilir biçimde kullanabilmesi de önemlidir. Kaynak teminindeki başarı projenin kalitesiyle doğrudan ilgilidir. Projenin sosyal ağlarda inandırıcı biçimde sunulması ve girişimcinin projenin başarıya ulaşacağına ilişkin güveni ve heyecanı sosyal ağlardaki sunumda yatırımcılara iyi yansıtılması da projenin kalitesi hususunda olumlu katkı üretebilecek hususlardır.

- Ülkemizde kitle fonlaması sisteminin gelişmesi önündeki en önemli engel yasa çerçeve eksikliği olarak görülmekteydi. Ancak Aralık 2017'de TBMM Genel Kurulunda kabul edilen torba yasayla kitle fonlama platformları sermaye piyasası kurumlarına dâhil edilmiştir. Şu aşamada SPK tarafindan nasıl bir kontrol sağlanacağı nasıl değişiklikler ön görüldüğü tahmin edilememektedir. Bu kapsamda gelişmeler araştırmacılar tarafından takip edilmeye muhtaçtır. Henüz belirsizlik aşaması geçilememiştir. Bu durum, sistemin aktörlerinin rolleri ve sorumluluk sınırlarının belirli olmayışı, sistemin işleyişine ilişkin önemli huşuların yeterince bilinmemesi gibi ciddi olumsuzluklara neden olarak sistemin uygulanmasını zorlaştırmakta ve gelişimini sinırlamaktadir. 


\section{KAYNAKÇA}

Akyüz, A. (2016). Sosyal medyada kitlelerin gücü: Kitlesel fonlama. In A. de Genel, M. G. (Edt.), Yeni medya araştırmaları - 2. (pp. 79-94). Ankara: Sonçağ Yayınları

Anadolu, B. (2006). Üreticinin çevrimiçi hali: Kitle kaynak yöntemi. In A. de Timisi, N. (Edt.), Dijital Kavramlar, Olanaklar, Deneyimler (pp. 127-153). İstanbul: Kalkedon Yayınları

Atsan, N., ve Erdoğan, E. O. (2015). Girişimciler İçin Alternatif Bir Finansman Yöntemi: Kitlesel Fonlama (Crowdfunding). Eskişehir Osmangazi Üniversitesi İ̈BF Dergisi, 10(1) 297-320. [Çevrim-içi: http://iibfdergi.ogu.edu.tr/makaleler/1247434_10-1_NISAN\%202015_Makale_0.pdf], Erişim tarihi: 05.12.2017.

Belleflamme, P., Lambert, T., ve Schwienbacher, A. (2013). Individual crowdfunding practices. Venture Capital: An International Journal of Entrepreneurial Finance, 1-21

Bock, A.J. \& Frydrych, D. (2016). The secret life of crowdfunding. The European Business Review, 29-36

Brüntje, D. \& Gajda, O. (Eds). (2015). Crowdfunding in Europe state of the art in theory and practice. U.S.A. : Springer Publishing

CanadaMediaFund. (2018). Using social media effectively for your crowdfunding campaign. CanadaMediaFund web Site, [Çevrim-içi: https://crowdfunding.cmf-fmc.ca/best practices/using-social-media-effectively-for-yourcrowdfunding-campaign]. Erişim tarihi: 17.02.2018.

Crowdfund.co. (2017). 4 Steps In The Crowdfundıng Campargn Process. Crowdfund Web Site, [Çevrim-içi: http://crowdfund.co/4-steps-in-the-crowdfunding-campaign-process], Erişim tarihi: 09.11.2017.

Crowdfundingblog.com. (2017, 8 Kasım). Most Successful Crowdfunding Campaigns. Crowdfundingblog Web Site, [Çevrim-içi: http://crowdfundingblog.com/most-successful-crowdfunding-projects], Erişim tarihi: 05.08.2017.

CrowdfundingHub. (2016). Current State of Crowdfunding in Europe. Amsterdam: Netherlands.

Cryptoturkiye.com. (2018, 24 Mart). ICO nedir?. Cryptoturkiye Web Site, [Çevrim-içi: https://cryptoturkiye.com/kesfet/ico-initial-coin-offering-nedir], Erişim tarihi: 24.03.2018.

Danmayr, F. (2013). Archetypes of crowdfunding platforms: A multidimensional comparison. U.S.A.: Springer Gabler Publishing

Ercan, S. (2017). Türkiye'de kitlesel fonlama: Destekçilerin motivasyonu. Ekonomi, İşletme ve Yönetim Dergisi, 1, 19

Ergen, M., Lau, J., ve Bilginoglu, K. (2013). Dağıtık girişimci sermayesi: Kitle fonlaması. Ankara: Bilim, Sanayi ve Teknoloji Bakanlığı 3. Sanayi Şurası

European Union. (2017, 4 Aralık). Crowdfunding Explained. European Union Web Site, [Çevrim-içi: https://ec.europa.eu/growth/tools-databases/crowdfunding-guide/what-is/explained_en], Erişim tarihi: 05.011.2017.

Futko, J. (2014, 24 Eylül). Equity vs. Debt Crowdfunding. Crowdfund Insider Web Site, [Çevrim-içi: https://www.crowdfundinsider.com/2014/09/50628-equity-vs-debt-crowdfunding], Erişim tarihi: 05.12.2017.

Gomez-Diago, G. (2016). The role of shared emotions in the construction of the cyberculture: From cultural industries to cultural actions: The case of crowdfunding. In A. de Tettegah S. (Edt.), Emotions, technology and social media (pp. 49-62). A.B.D. : Academic Press

Grut, O. W. (2016, 8 Ekim). Crowdfunding could face 'a shake out' after a 'slowdown in momentum'. Businessinsider Web Site, [Çevrim-içi: http://uk.businessinsider.com/altfi-crowdfunding-report-shows-2016-slowdown-2016-11], Erişim tarihi: 05.12.2017.

Halfacree, G. (2015). Crowdfunding's greatest hits. The Official Raspberry Pi Projects Book. 78-85

Karaarslan, M. H. ve Altuntaş, B. (2015). Sosyal pazarlamanın yeni aracı: Kitle fonlaması., Eskişehir: Anadolu Üniversitesi Yayınları

Kayhan, S.(2017). Fongogo: A case study on the usability of the local crowdfunding and fundraising websites in Turkey, Humanitas International Journal of Social Scienes, 9, 95-105

Mollick, E. (2013). The dynamics of crowdfunding: An exploratory study. Journal of Business Venturing, 29, 1-16

Nascimento, M., \& Querette, E. (2013). Crowdfunding: Challenges and Alternatives to Financing the Innovative Entrepreneurship in Brazil. Conference: 3rd Conference of the International Consortium of Studies on Innovation and Entrepreneurship (ICIER)-Policies to Support Entrepreneurship. [Çevrim-içi: 
https://www.researchgate.net/publication/260968782 Crowdfunding Challenges and Alternatives to Financing the _Innovative_Entrepreneurship_in_Brazil], Erişim tarihi: 05.12.2017.

Onur, M. N., ve Değirmenci, Ö. (2015). Crowdfunding - Kitle Fonlaması. Ankara: Türkiye. T.C. Başbakanlık Hazine Müsteşarlığı.

Ridgway, R. (2013). Crowdfunding: monetizing the crowd? In A. de Bazzichelli, T. \& Cox, G. (Eds.), Disrupting business: art and acivism in times of financial crisis (pp. 153-171). Williamsburgh: Autonomedia Publishing

Sahm, M., Belleflamme, P., Lambert, T., \& Schwienbacher A. (2013). Crowdfunding: Tapping the right crowd. Journal of Business Venturing, 29, 610-611

Scanlon, L. \& Gilbert, D. (2016). The art of crowdfunding. Start Your Own Business, 48-65

Schwienbacher A. \& Larralde B. (2010). Crowdfunding of small entrepreneurial ventures. In A. de Cumming, D. (Edt.), Handbook of entrepreneurial finance (pp. 369-389). New York: Oxford Press

Seyfi, M., Soydaş, U.A., ve Güven, D. (2017). Evaluating crowdfunding from the perspective of public relations. The Turkish Online Journal of Design, Art and Communication, 7, 150-162

Stark, C. (2016, 30 Haziran). Wearables Report: Was Pebble's \$12.8 million Kickstarter campaign a success? Stark Insider Web Site, [Çevrim-içi: http://www.starkinsider.com/2016/06/12-8m-pebbles-latest-kickstarter-success.html], Erişim tarihi: 05.12.2017.

Statisticbrain. (2016, 10 Eylül). Crowdfunding Industry Statistics. Staticbrain Web Site, [Çevrim-içi: http://www.statisticbrain.com/crowdfunding-platform-statistics], Erişim tarihi: 05.12.2017.

Strohmeyer, R. (2013). The crowdfunding caveat: Most campaigns fail. PCWorld Magazine Web Site, [Çevrim-içi: https://www.pcworld.com/article/2049399/the-crowdfunding-caveat-most-campaigns-fail.html], Erişim tarihi: 17.02.2018

The European Commission. (2017, 9 10). Crowdfunding. The European Commission Web Site: [Çevrim-içi: https://ec.europa.eu/info/business-economy-euro/growth-and-investment/financing-investment/crowdfunding en], Erişim tarihi: 05.12.2017.

The Guru Guide. (2016). Start Your Own Business - The Art of Crowdfunding. Money Matters. London: Future Publishing Limited.

Uyar, A. (2018, 28 Mart). Türkiye'de Startup Ekosistemini Yaratmak, Harvard Business Review, [Çevrim-içi: https://hbrturkiye.com/blog/turkiye-de-startup-ekosistemi-yaratmak], Erişim tarihi: 10.04.2018.

Wagner, E. T. (2014, 3 18). Equity Crowdfunding 101: Is It Right For Your Startup?. Forbes Web Site, [Çevrim-içi: https://www.forbes.com/sites/ericwagner/2014/03/18/equity-crowdfunding-101-is-it-right-for-yourstartup/\#2b868b4a6790], Erişim tarihi: 05.12.2017.

Zhang, B., Ziegler, T., Burton, J., Garvey, K., Wardrop, R., Lui, A., \& James, A. (2016). Sustaining Momentum - 2nd Annual European Alternative Finance Industry Report. Cambridge: England. Cambridge Judge Business School \& KPMG. 